\title{
Edelberto Torres-Rivas
}

Rafael Cuevas Molina*

Resumen: Los aportes de Edelberto Torres a la sociología de Centroamérica y de América Latina han sido ampliamente presentados, en especial desde su fallecimiento acaecido el 31 de diciembre del 2018. El presente texto pretende exponer, brevemente, algunos ángulos poco explorados de la vida y obra de quien, con frecuencia, ha sido catalogado como «el sociólogo de Centroamérica».

Palabras claves: sociología; Centroamérica; intelectualidad; Guatemala; exilio; Costa Rica; Edelberto Torres-Rivas.

Abstract: Edelberto Torres' contributions to the sociology of Central America and Latin America have been widely presented, especially since his death on December 31, 2018. The present text internes to present, briefly, some unexplored angles of the life work of who, frequently, has been classified as «the sociologist of Central America».

Keywords: Sociology; Central America; Intellectuals; Guatemala; Exile; Costa Rica; Edelberto Torres-Rivas.

1 T $\begin{aligned} & \text { o te pongás solemne» me diría Edelberto si supiera que escribiré so- } \\ & \text { bre él para una revista académica. Y yo pienso y repienso cómo debo } \\ & \text { escribir sobre Edelberto desde una perspectiva que no involucre los }\end{aligned}$ sentimientos. Edelberto era dos años menor que mi padre, y como él estudió derecho en la Universidad de San Carlos de Guatemala (USAC), en aquella facultad que hoy es museo pero que en esos tiempos bullía con la algarabía de los estudiantes. Hace unos años, cuando después de una larga ausencia de Guatemala volví a visitar el edificio en donde ambos fueron estudiantes a principios de los años 50, y mi padre decano en los 60, cuando Edelberto volvió a Guatemala y terminó la carrera, no pude contener las lágrimas al ver los sillones en donde alguna vez los vi conversando como viejos compañeros. Ahora se muestran como rastros de un tiempo ido, en el que ambos fueron protagonistas pero que aún vive en la memoria de los que vamos quedando para recordar y, eventualmente, decir algo sobre ellos.

Fecha de recepción: $21 / 01 / 2020$

* Guatemalteco. Doctor en Historia por la Universidad de La Habana (UH), Cuba. Profesor e investigador del Instituto de Estudios Latinoamericanos (IDELA) de la Universidad Nacional (UNA), Costa Rica. Artista plástico, pintor y escritor. Correo electrónico: rafael.cuevas.molina@una.ac.cr. 
Jorge Rovira y otros sociólogos han escrito sobre la obra de Edelberto'. Han hecho una presentación completísima de sus trabajos y los han analizado desde una óptica inquisitiva y sesuda. Hay poco que agregar a tal empresa. Así que lo que se pueda decir debería privilegiar otras miradas, otros ángulos que develen, tal vez, otras dimensiones de la importancia que tuvo Edelberto en las ciencias sociales de Centroamérica, pero no solo en ellas, sino también en la política, al igual que otros congéneres suyos, a los que mencionaré más adelante y que, como él — dignos representantes del tiempo que les tocó vivir- vieron en las ciencias sociales no solo instrumentos para explicarse las especificidades propias de Centroamérica, sino también para intervenir en el devenir turbulento de la política de la región.

Varias veces se ha dicho que Edelberto era, seguramente, el sociólogo más representativo de Centroamérica o, por lo menos, una de las figuras de referencia ineludible de los estudios sociológicos de la región. Ese papel preponderante de Edelberto en la sociología centroamericana se perfiló desde su primera publicación como sociólogo en toda regla, cuando Editorial Universitaria Centroamericana (EDUCA) sacó a la luz su trabajo Interpretación del desarrollo social centroamericano. Procesos y estructuras de una sociedad dependiente, en 1969.

Al decir sociólogo «en toda regla» estamos aludiendo a una característica de los cientistas sociales de la época, que tiene que ver con el grado de madurez que había alcanzado la formación de profesionales en ciencias sociales en la región centroamericana. Como es sabido, Edelberto era originalmente abogado, a pesar de que la facultad de la USAC en la que sacó su título de licenciado llevara el nombre de Facultad de Ciencias Jurídicas y Sociales.

Fue entonces por ese escrito que Edelberto se presentó a la sociedad académica de Centroamérica como sociólogo, lo cual constituía toda una novedad para la época. En este sentido, debe entenderse que, para la realidad centroamericana de ese momento histórico, el estudio de «lo social» o de «lo político» constituía, de por sí, motivo de sospecha por parte de los regímenes autoritarios que poblaban la región. Ser sociólogo era peligroso, y para las huestes de la derecha expresadas en organizaciones tan siniestras como el partido Movimiento de Liberación Nacional (MLN), autodenominado «partido de la violencia organizada» de Guatemala, sinónimo de subversivo.

En el caso guatemalteco, ambiente socio-político y académico del cual provenía Edelberto, de la Facultad de Ciencias Jurídicas y Sociales emergió una pléyade de profesionales comprometidos que, queriendo continuar su vocación política crítico-libertaria por los rumbos de la academia, se orientaron hacia ámbitos distintos a los del ejercicio de la abogacía que, por demás, muchos de sus excompañeros de universidad continuaron.

1 Por ejemplo: Jorge Rovira Mas; Marcia Rivera; Emir Sader; Marco A. Gandásegui, «Edelberto Torres-Rivas: dependencia, marxismo, revolución y democracia. La perspectiva desde la periferia», Crítica y Emancipación. Revista Latinoamericana de Ciencias Sociales, año 1, n. ${ }^{\circ} 2$ (enero-junio, 2009): 27-76, http:// biblioteca.clacso.edu.ar/ar/libros/secret/CyE/CyE2/. 
Seguramente un recorrido paralelo al de Edelberto en este sentido, aunque con su propia especificidad, es el de Carlos Guzmán Böckler, también graduado en la misma facultad, en el mismo período en el que se gradúa Edelberto. Al igual que él, Carlos Guzmán sale del país para poder especializarse en una ciencia social que le diera herramientas para aproximarse con mayor propiedad a la realidad socio-política. En su caso, el lugar elegido fue Francia y, como Edelberto, escoge el estudio de la sociología.

No es fruto de la casualidad el que dos intelectuales de la misma generación y provenientes de la misma facultad, cuyos aportes se transformarían en esenciales para entender la realidad contemporánea de la región, no solo buscaran nuevos horizontes de formación casi simultáneamente sino que, además, elaboraran también casi sincrónicamente sendos trabajos que, en su momento, se transformaron en referentes de la reflexión de nuestros países y que, tampoco por azar, tuvieran enormes similitudes en su sus respectivos títulos.

En el caso de Carlos Guzmán Böckler, en 1970 la prestigiosa editorial Siglo XXI Editores de México le publica, en coautoría con Jean-Loup Herbert, Guatemala, una interpretación histórico social, que se convertiría pronto en una sensación editorial que tendría ondas repercusiones en la forma de entender no solo la realidad guatemalteca sino, también, la praxis política de los movimientos que tenían como objetivo la transformación revolucionaria de la realidad.

Y para completar la mirada de los títulos que tendrían grandes consecuencias en las ciencias sociales de la época, no puede dejar de mencionarse el trabajo del historiador Severo Martínez Peláez quien, con La patria del criollo. Ensayo de interpretación de la realidad colonial guatemalteca publicado también en 1970 por la entonces recién creada Editorial de la Universidad de San Carlos de Guatemala, hizo acto de presencia en la discusión teórico conceptual, académica y política.

Cada uno de estos textos partía de tradiciones teóricas distintas, y cada uno encontró eco en proyectos editoriales diferentes pero que, también ellos, tenían elementos en común. La editorial que publicó a Edelberto fue EDUCA, referente de proyecto editorial de alcance regional no superado hasta nuestros días, con clara visión para publicar algunos de los libros más importantes de las ciencias sociales, la historia y la literatura de Centroamérica de la época, dirigida por Sergio Ramírez. Por su parte, la Editorial Universitaria de la Universidad de San Carlos de Guatemala, recién creada en 1970 en rectorado de mi padre, Rafael Cuevas del Cid, inaugura sus publicaciones precisamente con el texto de Severo Martínez Paláez, significando así, simbólicamente, la opción por una academia comprometida con el análisis de la realidad, pero también que apunta a consideraciones con importantes implicaciones políticas. Y, por último, el libro de Carlos Guzmán Böckler y Jean-Loup Ebert publicado por la prestigiosa editorial Siglo XXI Editores, en donde ningún centroamericano había publicado hasta 
entonces, y cuyas publicaciones era garantía de estar accediendo a los mejores análisis de las ciencias sociales de América Latina.

Creemos no errar si decimos que estos tres libros cimbraron las bases de las nacientes ciencias sociales de Centroamérica como ninguna otra publicación ha venido a hacerlo en años posteriores. Su lectura y discusión se hizo de forma apasionada en las entonces apenas nacientes facultades de ciencias sociales, proceso de institucionalización al que el mismo Edelberto aportaría, desde Costa Rica, de forma fundamental, aunque no exento de polémica.

Efectivamente, Edelberto volvió a Centroamérica desde México al establecerse en Costa Rica por invitación de Sergio Ramírez, a la sazón secretario general del Consejo Superior Universitario Centroamericano (CSUCA), en donde fundó el Programa Centroamericano de Ciencias Sociales apoyado por la Fundación Friedrich Ebert pero, también, con el financiamiento de la Fundación Ford que, en una Centroamérica cada vez más radicalizada políticamente, en la cual, apenas unos pocos años después, se vería triunfar la Revolución Sandinista en Nicaragua, y el avance de los procesos revolucionarios en El Salvador y Guatemala, se miraba con desconfianza ese tipo de acercamientos.

Así lo expresó el nuevo secretario general del CSUCA, Rafael Cuevas del Cid, quien en su país, Guatemala, había llevado como una de las reivindicaciones centrales de su campaña para la rectoría de la Universidad de San Carlos (19701974), el rechazo de un préstamo del Banco Interamericano de Desarrollo (BID) para la construcción de edificios en el nuevo campus de la zona 12 de la USAC en la ciudad capital, con el argumento que tales vinculaciones iban en contra de la independencia y la dignidad que debía mantener la academia respecto de instituciones de una u otra forma vinculadas con los Estados Unidos de América.

Fue en la pequeña oficinita en la que tenía su sede el mencionado programa en donde recuerdo haber visto por segunda vez en mi vida a Edelberto. La primera vez fue en una reunión en la casa de don Mardoqueo García, padre de Jorge Mario García Laguardia, camino a San Juan del Obispo en Antigua Guatemala, en donde en una tumultuosa reunión en la que solo creo haber visto a una mujer, Margarita Carrera, se concretó la candidatura a rector de la USAC de mi padre. En aquella bastante ascética oficina llena de documentos y papeles dispersos por todas partes, Edelberto trabajaba de espaldas a un pequeño patio interior en el que languidecían, a ojos vista, en unas macetas unas plantas jamás regadas por los cientistas sociales que se empeñaban por hacer florecer las ciencias sociales de la región.

El CSUCA era en ese entonces tal vez el espacio académico más importante de la región. Además de Edelberto, había otros colegas que colaboraban para perfilar ese esfuerzo por impulsar a las ciencias sociales centroamericanas. Entre ellos, debe mencionarse al brasileño Ciro Flamarión Cardoso y al argentino Héctor Pérez Brignoli, cuyo trabajo en colaboración tuvo una importancia fundamental para que la historiografía de Costa Rica, primero, y de Centroamérica después, accediera a las corrientes más contemporáneas. 
Pero no eran solo ellos. En 1973 un infausto golpe de Estado en Chile había provocado que una ola de exiliados de ese país, pero también de otros países del Cono Sur, llegara hasta Costa Rica. Se trataba de profesionales que tenían ya una práctica académica más consolidada en las ciencias sociales y que encontraron en el CSUCA, un organismo internacional en el que podían sobrellevarse con más facilidad los requerimientos burocráticos para establecerse en el país, un lugar en el cual aportar.

Aunque Edelberto jugó un papel fundamental en los distintos procesos que dieron origen a una serie de proyectos, programas e instituciones que cimentaron las bases para el desarrollo de las ciencias sociales en la región desde Costa Rica - papel que luego se prolongó con su paso por la secretaría general de la Facultad Latinoamericana de Ciencias Sociales (FLACSO), también con sede en San José, Costa Rica - no debe perderse de vista el papel y el aporte de todos estos profesionales que llegaron no solo desde el sur sino, también, desde las represoras repúblicas del resto de Centroamérica, como son los casos de los salvadoreños, ex rectores ambos de la Universidad de El Salvador (UES), Fabio Castillo y Rafael Menjívar.

Aunque a esas alturas de la vida Edelberto ya había abandonado las ideas políticas que, en las décadas anteriores, las de su juventud, lo habían acercado a la militancia comunista, su compromiso político no se vio mermado. Junto a Gabriel Aguilera quien, exiliado desde Guatemala se había asentado en San José y fundado el Instituto Centroamericano de Investigaciones Sociales (ICADIS), colaboró en la publicación de la revista Polémica, de cuyo consejo editorial formó parte junto a Mario Solórzano, también exiliado guatemalteco por aquellos años en Costa Rica, y que un tiempo después, ya de vuelta en Guatemala, fundaría y sería candidato presidencial del Partido Socialista Democrático.

El ambiente que se vivía en esa década de los 70 en Centroamérica, cuando Edelberto se asentó y trabajó en Costa Rica, bien podría catalogarse de pre revolucionario y esto se sentía en una Costa Rica en la que la impronta de la guerra sandinista contra la dictadura de Anastasio Somoza Debayle se apoyaba fuertemente. De ahí que también las ciencias sociales, los espacios en los que se cultivaban, las instituciones que las sustentaban, los proyectos y programas a través de los que se canalizaban, sintieran enérgicamente esa huella que llevaba a asumir, tal vez con mayor beligerancia, el compromiso político, y que puso su sello en todos los proyectos que se originaron en esos años, y no dejaron de tenerla aún en años posteriores.

Hacia finales de la década de los 80, por ejemplo, Edelberto fue pieza fundamental en el impulso de un proyecto de investigación, que reunió a un grupo importante de intelectuales centroamericanos y algunos estadounidenses que, como expresaban en la Introducción general, al escribirlo tenían los soterrados sentimientos de 
que sus textos tuvieran una polifónica vocación de futuro, ${ }^{2}$ y que dio como resultado la escritura de lo que se llamó la Historia general de Centroamérica en seis volúmenes, que fue publicada en España por la Editorial Siruelas en 1993, en el marco del 500 aniversario de la llegada de los europeos a América. Fue la primera historia de Centroamérica escrita y publicada desde, «la época de los liberales».

La última vez que vi a Edelberto fue en Guatemala un par de años antes de su muerte; ya se encontraba mermado de salud y presentía que se le estaba yendo la vida. Nuestra relación fue siempre de abajo hacia arriba; yo abajo, el hijo del amigo, el más joven, el que lo veía con respeto y cariño. Algo de paternidad y condescendencia había cuando se relacionaba conmigo, y así fue hasta el final. En ese tiempo, Edelberto se había transformado ya en una voz que era referencia no solo en Guatemala, a donde volvió, como me dijo sentado en su oficina de la Secretaria General de FLACSO, «porque ese es mi país», sino de la región y de la academia latinoamericana. En Guatemala, además, era una voz que se hacía presente con artículos de opinión ácidos y contundentes que se publicaban en la prensa, y que inmediatamente eran replicados por las redes sociales como voz de autoridad.

Ahora escribo sobre él para una revista académica a solicitud de un querido estudiante del que fui profesor hace unos años. Los afectos rodeándolo todo, seguramente coloreando los recuerdos y las valoraciones que se puedan hacer sobre él. Yo pienso que el tiempo irá dándole su lugar a Edelberto, y también creo que ese lugar no será menor, que estará ubicado como una figura importante de esta Centroamérica convulsa que nos tocó vivir, una figura que no se limitó solamente al ámbito de lo académico, o a eso que muchas veces nos han querido imponer: de una academia ascética, incontaminada; sino de una academia comprometida con su tiempo y sus necesidades, profundamente preocupada por aportar a todo lo que empujara hacia lo que dice la «Introducción general» de la Historia general de Centroamérica, y que seguramente escribió él: hacia una polifónica vocación de futuro.

Los Ángeles de San Rafael de Heredia, enero de 2020

\section{Bibliografía}

Comisión Coordinadora. «Introducción general». En Robert M. Carmack (ed.). Historia general de Centroamérica. Historia antigua. Volumen I. Madrid, España: FLACSO; Sociedad Estatal Quinto Centenario, 1993.

Rovira Mas, Jorge; Marcia Rivera; Emir Sader; Marco A. Gandásegui. «Edelberto Torres-Rivas: dependencia, marxismo, revolución y democracia. La perspectiva desde la periferia». Crítica y Emancipación. Revista Latinoamericana de Ciencias Sociales, año 1, n. ${ }^{\circ} 2$ (enero-junio, 2009): 27-76. http://biblioteca.clacso.edu.ar/ar/libros/secret/CyE/CyE2/.

2 Comisión Coordinadora, «Introducción general», en Robert M. Carmack (ed.). Historia general de Centroamérica. Historia antigua. Volumen I (Madrid, España: FLACSO; Sociedad Estatal Quinto Centenario, 1993), 9. 